\title{
Research of the Characteristic Dimension of the Transfers during the Convective Drying of the Sweet Potato for the Parallelepipedic and Spherical Shapes
}

\author{
Kondia Honoré Ouoba*, Abdou-Salam Ganame, François Zougmore \\ Laboratoire des matériaux et Environnement (LA.M.E.), Unité de Formation et de Recherche en Sciences Exactes et Appliquée \\ (UFR/SEA), Université de Ouaga I, Ouagadougou, Burkina Faso \\ Email: *ouobakahonore@yahoo.fr
}

How to cite this paper: Ouoba, K.H., Ganame, A.-S. and Zougmore, F. (2021) Research of the Characteristic Dimension of the Transfers during the Convective Drying of the Sweet Potato for the Parallelepipedic and Spherical Shapes. Advances in Materials Physics and Chemistry, 11, 267-276.

https://doi.org/10.4236/ampc.2021.1112022

Received: November 7, 2021

Accepted: December 27, 2021

Published: December 30, 2021

Copyright $\odot 2021$ by author(s) and Scientific Research Publishing Inc. This work is licensed under the Creative Commons Attribution International License (CC BY 4.0).

http://creativecommons.org/licenses/by/4.0/

\begin{abstract}
The aim of this work was to determine the characteristic dimension governing transfers during convective drying. Parallelepipedic and cylindrical form of sweet potato was used. For the parallelepipedic form P_L-l-e, the thickness e is set to $1 \mathrm{~cm}$ while the length $\mathrm{L}$ and the width 1 are varying. The results show that the variation of the other dimensions other than the thickness $\mathrm{e}$ does not influence the transfers in a considerable way. The same observation is made for the cylindrical samples $c_{-}$H-R by keeping the radius $\mathrm{R}$ constant. This present work therefore allows us to conclude that the thickness of the parallelepiped shaped samples and the radius of the cylindrical shapes, all being the smallest dimensions, characterize the transfers.
\end{abstract}

\section{Keywords}

Drying, Initial Size, Characteristic Dimension, Forms

\section{Introduction}

The drying of agrifood products is taking on a considerable scale [1] [2]. However, the quality of the finished product often leaves something to be desired [3]. It is uncommon to see micro-drying enterprises with uniform stocks of dried products. These problems which plague the development of the field of drying are a consequence of the failure to master transfers during drying [4] [5] [6]. Indeed, multiple parameters complicate the evaluation of transfers. We distinguish the external parameters [7] [8], especially related to the drying environment [9] 
Maskan (2001) kiwifruits, [10] Doymaz (2007) for tomato, [11] Desmorieux et al. (2005) for spirulina, parameters intrinsically linked to the nature of the product [12] [13] [14], but also parameters linked to the pretreatment of samples. Among these preprocessing parameters, cutting plays an important role [15]-[19]. Dryers in sub-Saharan Africa manually cut the product. We therefore obtain a mixture of shapes and sizes that are exposed to drying. The studies of [1], showed that the size and the shape are important parameters in the evaluation of the convective drying of agrifood products. Ouoba, 2013 [1] suggested the existence of characteristic dimensions which could dictate the transfers during their convective drying, and which bypasses the effect of the shape as indicated in Figure 1. It is defined as being the shortest path that the heat will take to reach the water farthest from the drying environment. In other words, it is also the path that the last water molecule will take, the one that is farther from the outside, to be evacuated to the outside.

This present work consists in determining this characteristic dimension for the samples of sweet potato of parallelepipedal and cubic shapes. We have fixed the characteristic dimension in the direction of the thickness of the samples of parallelepiped shape and of the radius for the samples of cylindrical shape.

\section{Materials and Methods}

\subsection{Preparation of Samples}

A homogeneous macrostructured material sweet potato (Ipomoea batatas) is used to minimize the effects of macrostructure and component composition [18] on the evaluation of transfers during convective drying. Thereby, the sweet potato tubers were used as an experiment for this present work.

The tubers that served as samples for our experiments were purchased in a local market in the same heap in batches in order to reduce the differences in

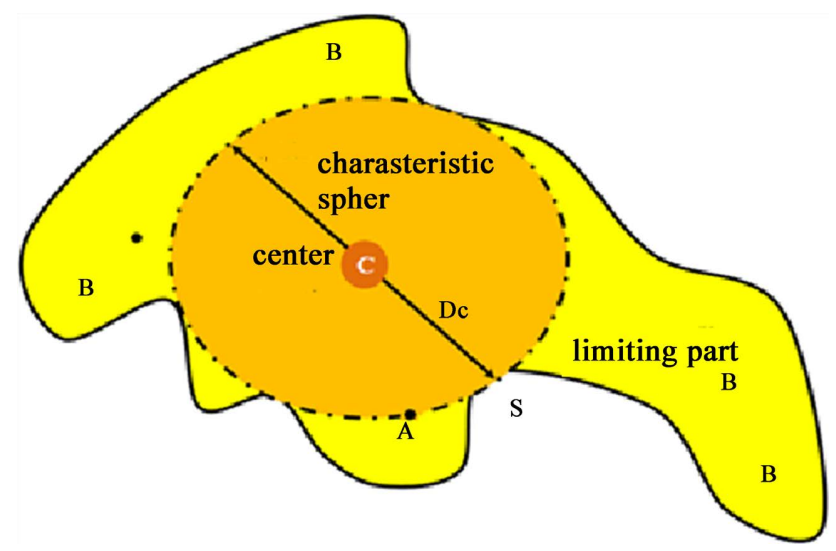

Figure 1. Concept of the characteristic radius: largest sphere cut from a specimen of any shape (characteristic diameter Dc the diameter of this sphere). The center (C) of the characteristic sphere contains the humidity furthest from the exchange surface (S). The parts limiting transfers (B) constitute a brake on transfers in the characteristic sphere. Thus, the points A of the characteristic sphere are not directly exposed to drying, Ouoba, 2013 [1]. 
material properties [13]. The potato is therefore transported to the University Nazi BONI of Bobo-Dioulasso, Burkina Faso. The tubers are washed, peeled and cut manually into the desired shape (Figure 2) and size using a stainless steel knife. the use of the stainless steel knife prevents the oxidation of surfaces in contact with the oxygen in the air. The cut samples are quickly immersed in water to prevent oxidation and to evacuate excess starch from the surface which forms a film that slows down transfers.

\subsection{Drying Process}

Washed and wiped with blotting paper, the samples are placed in the oven, the temperature of which is suitably adjusted for drying. We used an AIR concept, temperature varying from $40^{\circ} \mathrm{C}$ to $250^{\circ} \mathrm{C}$, with PID regulation, with digital display. The samples are regularly withdrawn for the determination of the mass during the drying time and reintroduced into the oven. The mass is determined by a balance (SARTORIUS, $0.001 \mathrm{~g}$ precision, France). The measurement time is fast so as not to disturb the thermodynamic equilibrium. Given the regular withdrawal of samples, we consider that the transfers take place on all sides. The samples are placed directly on the racks. We calculate the initial areas as the total area of the sample from the dimensions measured with a Mitutoyo (Japan) precision 2.10 - $5 \mathrm{~mm}$ micrometer. Note that we were unable to measure air speed and relative humidity which are important parameters in the evaluation of drying. To do this, we compare the results of experiments which were carried out simultaneously and in the same oven to circumvent the influence of these two parameters.

The determination of the dry mass is made after a stay of 24 hours in an oven at $70^{\circ} \mathrm{C}[20]$ (AOAC, 1990).

\section{Data Exploitation}

\subsection{Water Content}

The initial water content of the product is the quotient of the total mass of water contained in the freshly cut product $m_{e}$ divided by the mass of solid matter $m_{s}$.

$$
X_{0}=\frac{m_{e}}{m_{s}}=\frac{m_{0}-m_{s}}{m_{s}}
$$

where $m_{0}$ is the initial mass of the sample and $m s$ is the dry mass of the sample.

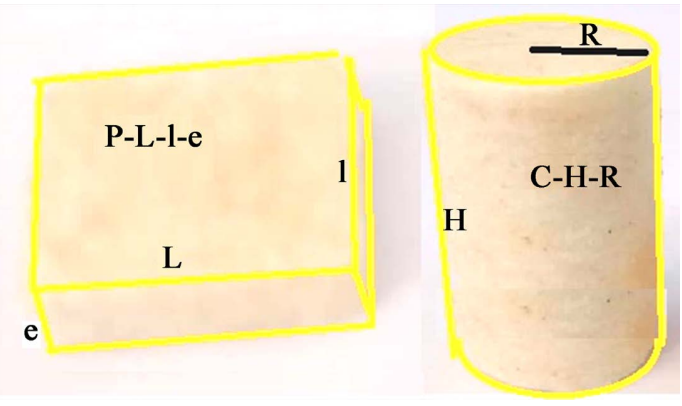

Figure 2. Type of shape, parallelepipedic P-L-l-e and cylinder C-H-R. 
The curves of the water contents as a function of the drying time were drawn from the experimental data. From the mass of the sample at time $t$, we deduce the water content according to:

$$
X(t)=\frac{m(t)-m_{s}}{m_{s}}
$$

where $m(t)$ is the mass of the sample at time $t$ of drying.

\subsection{Drying Kinetics}

From the value of the mass $m(t)$ and the dry mass $m_{s}$ of the sample we calculate the water content $X(t)$ according to the equation Eq-2. The relation $X(t)$ - $t$ gives us the kinetics of the variation of the water content of the product. To have the same basis for comparison, we normalize the water content at time $t$ by the initial water content $X_{0}$ of the product determined according to the Equation (1), which gives us the $X / X_{0}$ - $t$ curves.

\section{Results and Discussion}

\subsection{Validation of the Experiment Results}

Figure 3 contains the results of the tests on the parallelepiped shape samples. The same thickness $\mathrm{e}=1 \mathrm{~cm}$ is set for all the samples while the lengths and the widths $\mathrm{L} \times 1$ vary for the purposes of experiments. The $\mathrm{L} \times 1 \times \mathrm{e}$ dimensions of 3 $\mathrm{cm} \times 2 \mathrm{~cm} \times 1 \mathrm{~cm}, 4 \mathrm{~cm} \times 2 \mathrm{~cm} \times 1 \mathrm{~cm}, 4 \mathrm{~cm} \times 3 \mathrm{~cm} \times 1 \mathrm{~cm}$ and $5 \mathrm{~cm} \times 3 \mathrm{~cm} \times 1$ $\mathrm{cm}$ are used. We denote them respectively $\mathrm{P} \_L_{-}=3-1=2-\mathrm{e}=1, \mathrm{P}_{-} \mathrm{L}=4-1$
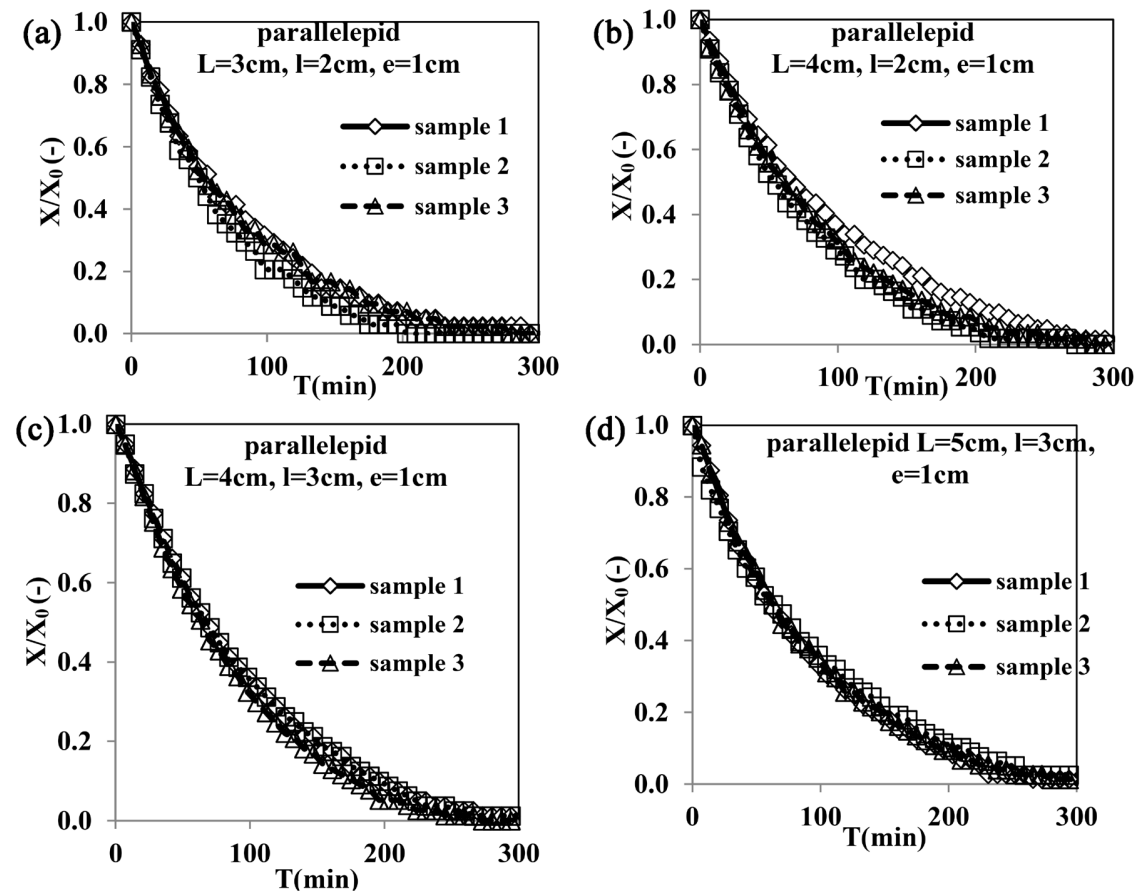

Figure 3. Validation of the results on the parallelepipedal samples P_L-l-e of sweet potato: (a) P_L = 3-1=2-e =1; (b) P_L $=4-1=2-\mathrm{e}=1$; (c) $\mathrm{P} \_\mathrm{L}=4-1=3-\mathrm{e}=1$; (d) P_L $=5-1=3-\mathrm{e}=1$. 
$=2-\mathrm{e}=1, \mathrm{P} \_\mathrm{L}=4-\mathrm{l}=3-\mathrm{e}=1$ and $\mathrm{P} \_\mathrm{L}=5-1=3-\mathrm{e}=1$. For each type of sample, three measurements are used to ensure the reliability of the experiments. The results show that the differences between the curves are minimal, going close to zero (0) $\mathrm{kg}_{\mathrm{e}} / \mathrm{kg}_{\mathrm{ms}}$ for the most repetitive ones to 0.109 obtained, as the worst case, for samples 1 and 2 of the parallelepipedal samples $P_{-} L=4-1=2-$ $\mathrm{e}=1$ at the $161^{\text {st }}$ minute of drying. These small differences can be attributed to imperfect measurements, but also to the complex nature of agrifood products.

Figure 4 gathers the results of the experiment on the cylindrical samples, of the same radius $\mathrm{R}=1 \mathrm{~cm}$. Heights $\mathrm{H}$ vary from experiment to experiment. The heights $\mathrm{H}$ of $2 \mathrm{~cm}, 3 \mathrm{~cm}, 4 \mathrm{~cm}$ and $5 \mathrm{~cm}$ are used. For each type of sample, three are used to ensure the reliability of the experiments. The results show that the differences between the curves are ranging from almost zero $\left(0 \mathrm{~kg}_{\mathrm{e}} / \mathrm{kg}_{\mathrm{ms}}\right)$ for the most repetitive to $0.114 \mathrm{~kg}_{\mathrm{e}} / \mathrm{kg}_{\mathrm{ms}}-0.079 \mathrm{~kg}_{\mathrm{e}} / \mathrm{kg}_{\mathrm{ms}}=0.035 \mathrm{~kg}_{\mathrm{e}} / \mathrm{kg}_{\mathrm{ms}}$ obtained for samples 1 and 2 of the cylinders $\mathrm{C}_{-} \mathrm{H}=2-\mathrm{R}=1$ at the $175^{\text {th }}$ minute of drying. These insignificant differences can be attributed to imperfect measurements, but also to the complex nature of agrifood products.

\subsection{Thickness as Characteristic Dimension of Drying of Parallelepipedal Samples}

In this paragraph we seek to verify if the thickness e of the samples in parallelepiped
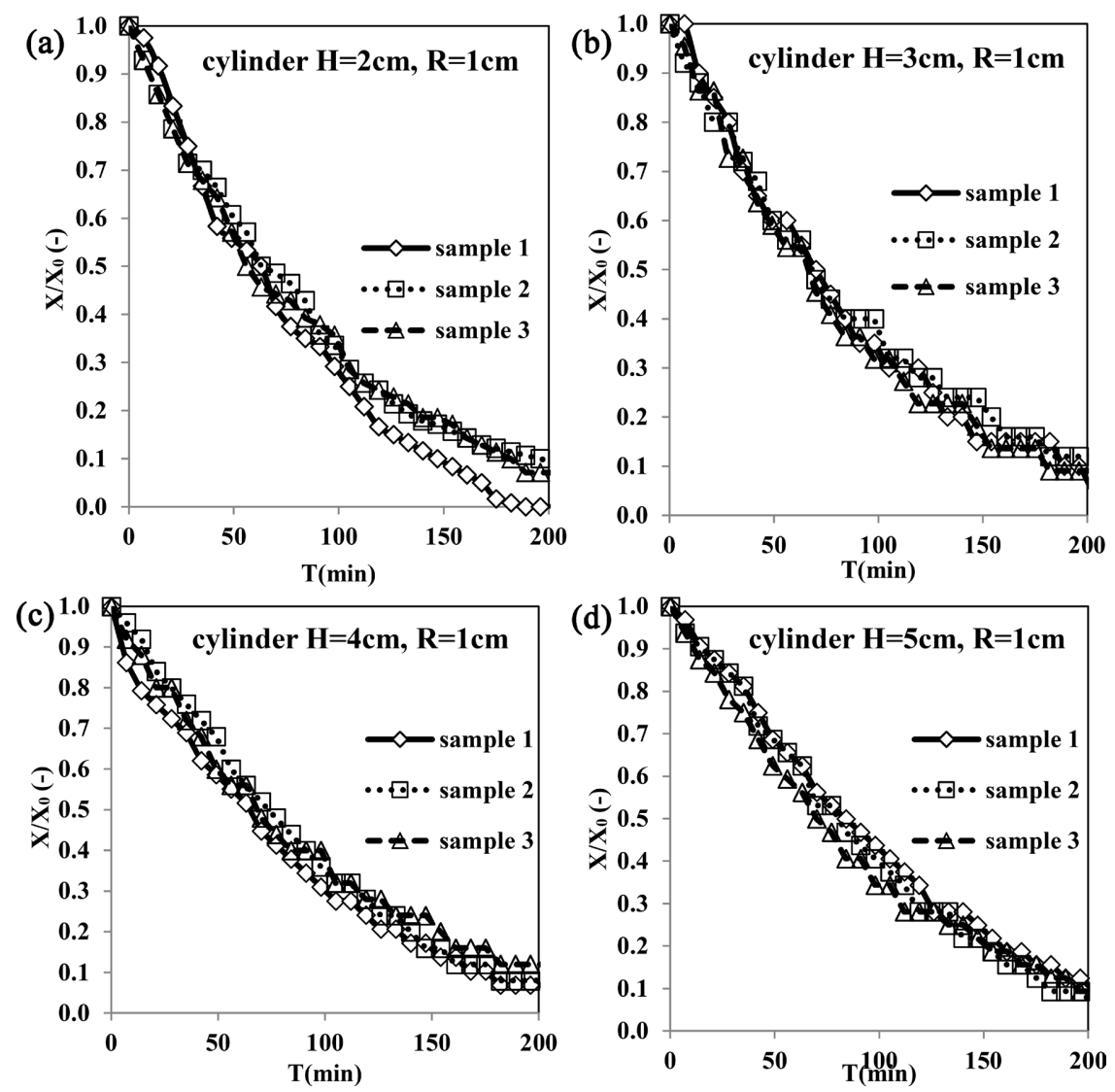

Figure 4. Validation of the radius of the cylindrical samples c_H-R of sweet potato: (a) C_H $=2-\mathrm{R}=1$; (b) C_H $=3-\mathrm{R}=1$; (c) $\mathrm{C} \_\mathrm{H}=4-\mathrm{R}=1$; (d) $\mathrm{C} \_\mathrm{H}=5-\mathrm{R}=1$. 
shape is the characteristic dimension of drying. Indeed, according to Ouoba, 2013 [1] the smallest path for the migration of water from the inside of the product to the outside in this case would be the thickness. This is the smallest dimension compared to the length and width of the samples.

To do this, we have set a thickness e $=1 \mathrm{~cm}$ facing lengths of $3 \mathrm{~cm}, 4 \mathrm{~cm}, 5 \mathrm{~cm}$ and widths of $2 \mathrm{~cm}, 3 \mathrm{~cm}$. the sample is denoted here P_L-l-e according to the dimensions length $\mathrm{L}$, width 1 , thickness e used for these parallelepipedic shapes P.

Figure 5 contains the results from the convective drying of these different samples. The average of the normalized water contents $X / X_{0}$ of the three tests by type of sample is plotted as a function of the drying time. This average makes it possible to reduce the differences in handling errors and difficulties linked to the nature of the product. As we can see, the results are very superposable.

The maximum standard water content deviation is $0.223 \mathrm{~kg}_{\mathrm{e}} / \mathrm{kg}_{\mathrm{ms}}-0.144$ $\mathrm{kg}_{\mathrm{e}} / \mathrm{kg}_{\mathrm{ms}}=0.079 \mathrm{~kg}_{\mathrm{e}} / \mathrm{kg}_{\mathrm{ms}}$ between P_L $=3-\mathrm{l}=2-\mathrm{e}=1$ and P_L $=5-1=4-\mathrm{e}$ $=1$ at the $140^{\text {th }}$ minute of drying. this difference is negligible and occurs when the material undergoes visible deformations of its structure which can also interfere with the transfer path.

\subsection{Radius as Characteristic Dimension of Drying of Cylindrical Samples}

The search for the characteristic dimension continues here with the cylindrical samples. We look for it in the radial direction, fixing the radius $\mathrm{R}=1 \mathrm{~cm}$ as the smallest dimension. This corroborates the idea of Ouoba, 2013 [1], as a smaller

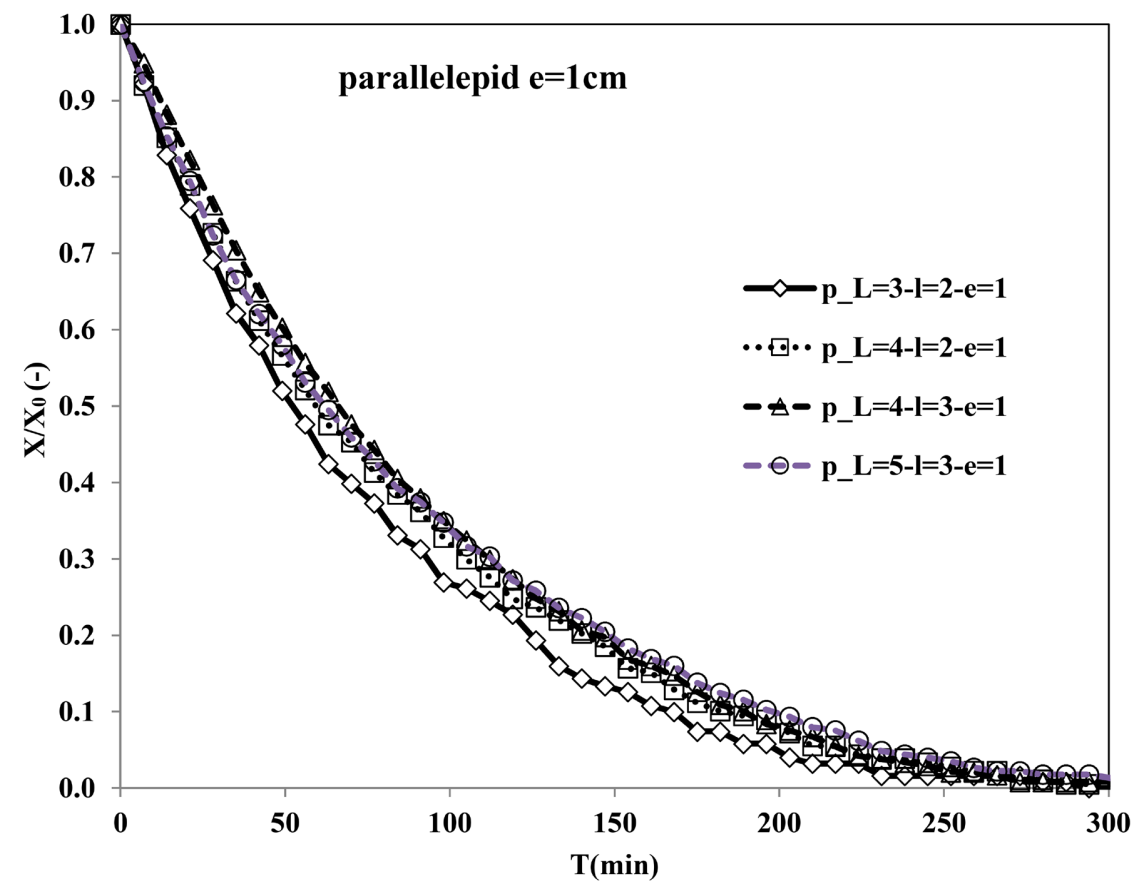

Figure 5. Validation of the thickness e of the parallelepiped P_L-1-e as a characteristic dimension of transfers during convective drying of the sweet potato. 
path for the migration of water from the inside to the outside of the product. This is the smallest dimension compared to the height of the samples.

To do this, we have set a radius $\mathrm{R}=1 \mathrm{~cm}$ facing heights of $2 \mathrm{~cm}, 3 \mathrm{~cm}, 4 \mathrm{~cm}$ and $5 \mathrm{~cm}$. The sample is denoted here $\mathrm{C} \_\mathrm{H}-\mathrm{R}$ according to the dimensions height $\mathrm{H}$, radius $\mathrm{R}$ used for these cylindrical shapes $\mathrm{c}$.

Figure 6 contains the results from the convective drying of these different samples. The average of the normalized water contents $X / X_{0}$ of the three tests by type of sample is plotted as a function of the drying time. The goal is to reduce the effects of handling and difficulties linked to the nature of the product.

Here also, it can be seen, according to Figure 6, that the results are indeed superposable.

The maximum standard water content deviation is $0.302 \mathrm{~kg}_{\mathrm{e}} / \mathrm{kg}_{\mathrm{ms}}-0.217$ $\mathrm{kg}_{\mathrm{e}} / \mathrm{kg}_{\mathrm{ms}}=0.085 \mathrm{~kg} / \mathrm{kg}_{\mathrm{ms}}$ between $\mathrm{c}_{-} \mathrm{H}=2-\mathrm{R}=1$ and $\mathrm{c}_{-} \mathrm{H}=5-\mathrm{R}=1$ at the $119^{\text {th }}$ minute of drying. This difference is also negligible and occurs when the material undergoes visible deformations of its structure as well.

\subsection{Characteristic Dimension for Parallelepiped and Spherical Forms}

From the foregoing, the thickness of the parallelepiped samples turns out to be the dimension which best governs the transfers versus its length and its width. Likewise, with regard to cylindrical samples, the fixed radius smaller than the height is the characteristic dimension of the transfers in the product during its convective drying.

In any case, the thickness and the radius in this present work are the smallest

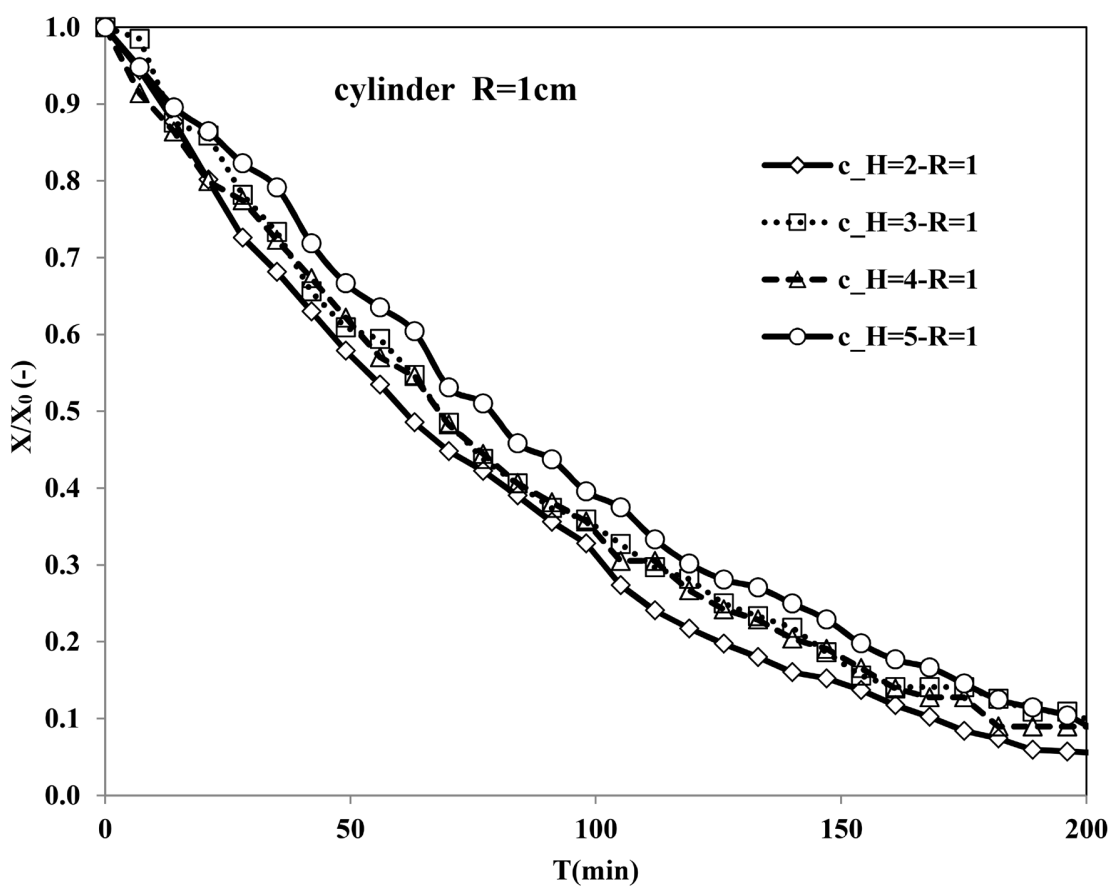

Figure 6. Validation of radius $\mathrm{R}$ of cylinder C_H-R as characteristic dimension of transfers during convective drying of sweet potato. 
dimensions. According to, Ouoba, 2013 [1], we can affirm that these dimensions of thickness and radius constitute the shortest path for the migration of heat to the most remote point of the drying environment. They are also the shortest path for the water furthest from the outside to be able to escape from the grip of matter.

For these samples of parallelepipedal and cylindrical shape, the notion of characteristic dimension, as being the shortest distance between the outside and the point most unfavorable for drying is verified.

\section{Conclusions}

This work highlights the importance and the existence of a characteristic dimension that dictated the transfers during the convective drying of organic products such as sweet potato.

So, for two forms, parallelepipedal and spherical forms, cut in sweet potato material are considered to be homogenous. The most important is the characteristic dimension described by Ouoba, 2013 [1].

In the case of samples with parallelepipedic shape, this characteristic dimension is the smallest dimension, i.e. the thickness. Indeed, for different lengths and widths Lxl ranging from $2 \mathrm{~cm} \times 2 \mathrm{~cm}, 3 \mathrm{~cm} \times 2 \mathrm{~cm}, 4 \mathrm{~cm} \times 2 \mathrm{~cm}, 5 \mathrm{~cm} \times 2$ $\mathrm{cm}$, all having the same thickness $\mathrm{e}=1 \mathrm{~cm}$ dry in a similar way.

In the case of samples of cylindrical shape, this characteristic dimension is, for these present works, the radius which is the smallest dimension. Indeed, for different heights $\mathrm{H}$ ranging from $2 \mathrm{~cm}, 3 \mathrm{~cm}, 4 \mathrm{~cm}$ and $5 \mathrm{~cm}$, all having the same radius $=1 \mathrm{~cm}$ dry similarly.

This work corroborates the notion of characteristic dimension described by Ouoba, 2013 [1], and reveals to be the smallest dimension of the sample exposed to drying, with regard to the two shapes, parallelepiped and spherical used.

It would therefore be recommended that dryers consider this characteristic dimension for uniform drying of the organic products to be dried.

Also, to deepen the importance of the notion of the characteristic dimension, wider experiments, varying the shapes and sizes are to be carried for further studies.

\section{Conflicts of Interest}

The authors declare no conflicts of interest regarding the publication of this paper.

\section{References}

[1] Ouoba, K.H. (2013) Séchage des produits agroalimentaires: Influence de la taille, de la forme et de la découpe. Thèse de doctorat Unique, Université de Ouagadougou, Burkina Faso.

[2] Doymaz, I. and Pala, M. (2002) Hot-Air Drying Characteristics of Red Pepper. Journal of Food Engineering, 55, 331-335. https://doi.org/10.1016/S0260-8774(02)00110-3 
[3] Ouoba, K.H., Zougmore, F., Naon, B. and Desmorieux, H. (2012) Profils des teneurs en eau de la patate douce durant son séchage convectif (Profile of Sweet Potato Water Content during Its Convective Drying). Revue du CAMES Série A, 13, 201-205.

[4] Ouoba, K.H., Desmorieux, H. and Zougmoré, F. (2019) What Process Optimizes Convective Drying of Farm Products with Complex Constitution: Case of Okra (Abelmoschus esculentus). Journal of Agricultural Chemistry and Environment, 8 , 14-22. https://doi.org/10.4236/jacen.2019.81002

[5] Ganame, A.-S., Ouoba, K.H. and Zougmore, F. (2020) Consideration of Size and Dimension in the Evaluation of Transfers during Convective Drying of Sweet Potato). Journal of Analytical Sciences, Methods and Instrumentation, 10, 104-112. https://doi.org/10.4236/jasmi.2020.104008

[6] Doymaz, I. (2005) Drying Characteristics and Kinetics of Okra. Journal of Food Engineering, 69, 275-279. https://doi.org/10.1016/j.jfoodeng.2004.08.019

[7] Khraisheh, M.A.M., Cooper, T.J.R. and Magee, T.R.A. (1997) Microwave and Air Drying I. Fundamental Considerations and Assumptions for the Simplified Thermal Calculations of Volumetric Power Absorption. Journal of Food Engineering, 33, 207-219. https://doi.org/10.1016/S0260-8774(97)00050-2

[8] Jayaraman, K.S., Das Gupta, D.K. and BabuRao, N. (1990) Effect of Pre-Treatment with Salt and Sucrose on the Quality and Stability of Dehydrated Cauliflower. International Journal of Food Science and Technology, 25, 47-60. https://doi.org/10.1111/j.1365-2621.1990.tb01058.x

[9] Maskan, M. (2001) Drying, Shrinkage and Rehydration Characteristics of Kiwifruits during Hot Air and Microwave Drying. Journal of Food Engineering, 48, 177-182. https://doi.org/10.1016/S0260-8774(00)00155-2

[10] Doymaz, I. (2007) Air-Drying Characteristics of Tomatoes. Journal of Food Engineering, 78, 1291-1297. https://doi.org/10.1016/j.jfoodeng.2005.12.047

[11] Desmorieux, H. and Decaen, N. (2005) Convective Drying of Spirulina in Thin Layer. Journal of Food Engineering, 66, 497-503.

https://doi.org/10.1016/j.jfoodeng.2004.04.021

[12] Ganame, A.-S., Ouoba, K.H. and Zougmore, F. (2020) Taking into Account the Complex Nature and the Intrinsic Parameters of Agro-Food Products during Convective Drying. Journal of Biophysical Chemistry, 11, 1-13. https://doi.org/10.4236/jbpc.2020.111001

[13] Ouoba, K.H., Zougmoré, F., Sam, R., Toguyeni, A. and Desmorieux, H. (2014) Characterization of Okra Convective Drying, Influence of Maturity. Food and $\mathrm{Nu}$ trition Sciences, 5, 590-597. https://doi.org/10.4236/fns.2014.56069

[14] Ouoba, K.H., Zougmoré, F. and Desmorieux, H. (2019) Effect of Farm Product Intrinsic Properties on Convective Drying: Case of Okra. American Journal of Plant Sciences, 10, 101-110. https://doi.org/10.4236/ajps.2019.101009

[15] Villa-Corrales, L., Flores-Prieto, J.J., Xamán-Villaseñor, J.P. and García-Hernández, E. (2010) Numerical and Experimental Analysis of Heat and Moisture Transfer during Drying of Ataulfo Mango. Journal of Food Engineering, 98, 198-206. https://doi.org/10.1016/j.jfoodeng.2009.12.026

[16] Pala, M., Mahmutoglu, T. and Saygi, B. (1996) Effects of Pretreatments on Quality of Open-Air and Solar Dried Apricots. Nahrung Food, 40, 137-141. https://doi.org/10.1002/food.19960400308

[17] Ouoba, K.H., Zougmoré, F. and Desmorieux, H. (2018) Effect of Initial Size and Shape Importance on Masse Transfer during Convective Drying. Food and Nutri- 
tion Sciences, 9, 1514-1524. https://doi.org/10.4236/fns.2018.912109

[18] Ouoba, K.H., Desmorieux, H., Zougmoré, F. and Naon, B. (2010) Caractérisation du séchage convectif du gombo, influence de la découpe et de ses constituants. Afrique Science, 6, 37-48.

[19] Hatamipour, M.S. and Mowla, D. (2003) Correlations for Shrinkage, Density and Diffusivity for Drying of Maize and Green Peas in a Fluidized Bed with Energy Carrier. Journal of Food Engineering, 59, 221-227.

https://doi.org/10.1016/S0260-8774(02)00461-2

[20] AOAC (1990) Official Methods of Analysis No. 934-06. Association of Official Chemists, Washington DC. 